\title{
Neoplasia Sólida Pseudopapilar do Pâncreas: Relato de Caso
}

\section{Solid Pseudopapillary Neoplasm of the Pancreas: Case Report}

Francisca M. Pereira ${ }^{1 *}$, Cristina Marques ${ }^{1}$, Joana Esteves ${ }^{1}$, Maria Boncoraglio, Ana Martins², Daniel Martins²

\section{RESUMO}

A investigação de adenopatia é muito comum na prática clínica, e pode ser complexa face às múltiplas etiologias possíveis. No presente caso, o aparecimento de tumefação cervical num jovem de 25 anos, do sexo masculino, e sua investigação clínica adicional levou ao achado de uma neoplasia sólida pseudopapilar do pâncreas. Os autores discutem a entidade, cuja prevalência é rara, bem como o diagnóstico e abordagem recomendadas.

PALAVRAS-CHAVE: Carcinoma Papilar; Neoplasias Pancreáticas

\section{ABSTRACT}

Investigation of patients with unexplained lymphadenopathy is very common in clinical practice and may be caused by a wide range of conditions. In the present case, the onset of cervical swelling in a 25-year-old man, led to the diagnosis of solid pseudopapillary neoplasm of the pancreas. The authors discuss the diagnosis and recomended management of this rare condition. KEYWORDS: Carcinoma, Papillary; Pancreatic Neoplasms 


\section{INTRODUÇÃO}

A neoplasia sólida pseudopapilar do pâncreas é um tumor maligno de baixo grau, que representa cerca de 0,9\%-2,7\% dos tumores pancreáticos exócrinos e 5\% dos tumores quísticos. ${ }^{1}$ Afeta predominantemente muIheres jovens, tendo pico de incidência entre os 20-30 anos de idade. Caracteriza-se por ser um tumor de crescimento indolente, sendo a recidiva local e metastização raras, com elevada taxa de cura após ressecção completa da lesão. ${ }^{2}$

Os autores realçam o presente caso pela sua baixa prevalência, sobretudo em indivíduos do sexo masculino.

\section{CASO CLÍNICO}

Jovem do sexo masculino, de 25 anos de idade, sem antecedentes pessoais relevantes prévios. Referenciado para a consulta externa de medicina por tumefação cervical direita com 1 mês de evolução, sem sinais inflamatórios associados e sem resposta a antibioterapia instituída (amoxicilina/ácido clavulânico). Sem queixas constitucionais ou outros sintomas associados, nomeadamente febre ou perda ponderal. Trazia ecografia de partes moles do pescoço realizada em ambulatório, que confirmava nódulo à direita com 20×75×12,5 mm com vários gânglios adjacentes, bem como vários gânglios à esquerda, o maior com 15×4,3 mm.

À observação apresentava tumefação dura, heterogénea, móvel e indolor, na região cervical lateral direita com cerca de $3 \mathrm{~cm}$ de diâmetro, bem como adenopatia móvel e indolor, com cerca de $1 \mathrm{~cm}$ na região cervical esquerda. Restante exame objetivo sem alterações, nomeadamente sem outras adenopatias periféricas ou hepato-esplenomegalia palpáveis. Pedida observação por Otorrinolaringologia, que excluiu alterações desse foro.

No decurso da investigação etiológica, foi pedido estudo analítico sem alterações significativas, nomeadamente sem elevação dos parâmetros inflamatórios (VS normal, PCR negativa), hemograma com fórmula leucocitária normal, LDH normal. Enzimologia hepática dentro dos valores referência. Serologias víricas (HIV, HBV, HCV, CMV; EBV) negativas; toxoplasma gondii IgG e IgM negativas. Radiografia torácica com índice cardiotorácico normal, sem alargamento do mediastino ou alterações pleuro-parenquimatosas.

Submetido a exérese de gânglio cervical direito, com exame cultural e pesquisa de BK negativos. Histologia compatível com hiperplasia folicular reativa associada a linfadenite granulomatosa não necrotizante.
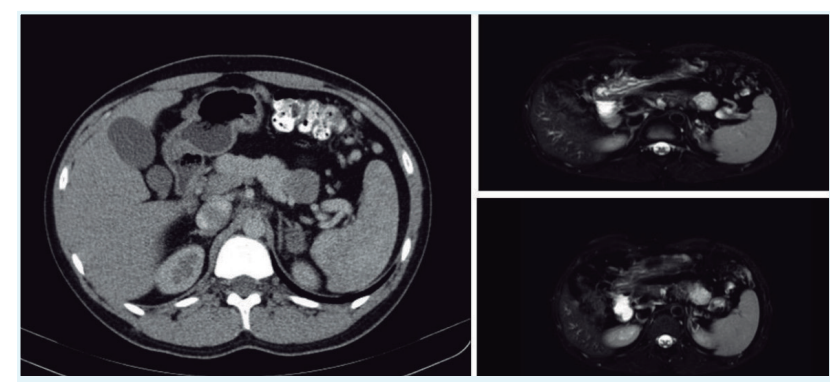

FIGURA 1. Corte axial de TC abdominal (esquerda) e cortes de RM abdominal (direita) a revelar massa cauda do pâncreas.

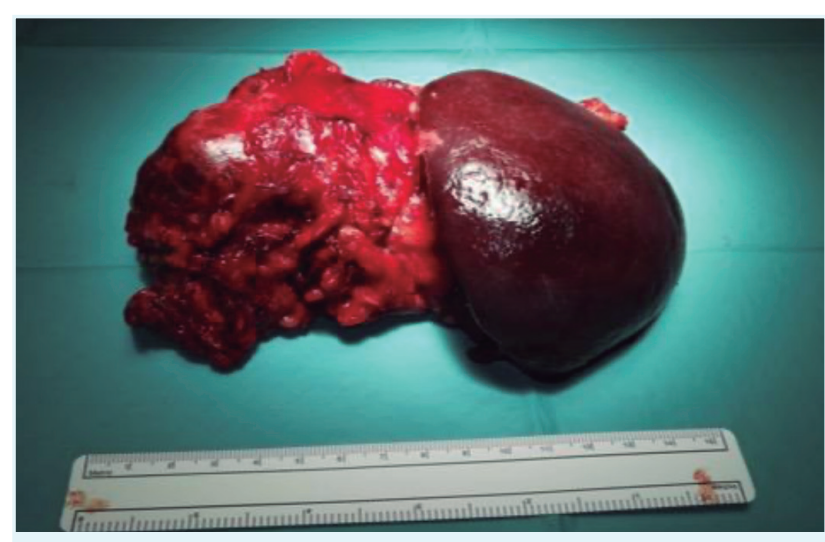

FIGURA 2. Peça cirúrgica da lesão removida em bloco, com esplenectomia concomitante.

Tomografia computorizada (TC) abdomino-pélvica com presença de massa na cauda do pâncreas com $6 \times 6,6 \mathrm{~cm}$ com algumas calcificações periféricas, hipovascular, a condicionar trombose do 1/3 distal da veia esplénica; marcada ectasia das veias gástricas curtas, arcadas gastro-epiplóicas e tributárias da veia gástrica esquerda, com hipertensão portal esquerda decorrente da trombose da veia esplénica (Fig. 1, esquerda). Para melhor caracterização foi pedida ressonância magnética (RM) abdominal que confirmou massa de $6 \mathrm{~cm}$ na cauda do pâncreas, com múltiplas formações quísticas no seu interior, com bordos irregulares, mas bem definidos, e captação de contraste endovenoso apenas pelas suas paredes e pelos septos no seu interior, levantando como hipótese diagnóstica de eventual cistadenoma microquístico (Fig. 1, direita). Revelou ainda compressão e invasão da veia esplénica, assim como contacto com o hilo esplénico e vísceras ocas do hipocôndrio e flanco esquerdos, mas sem sinais de invasão direta.

Submetido a ressecção cirúrgica da lesão, em bloco, com esplenectomia concomitante (Fig. 2), com aspeto morfológico e imunohistoquímico compatíveis com neoplasia sólida pseudopapilar do pâncreas; estadiamento pT3NO (Fig. 3). Mantém-se em follow-up, sem recidiva de doença aos 3 anos, nem recorrência de adenopatias. 


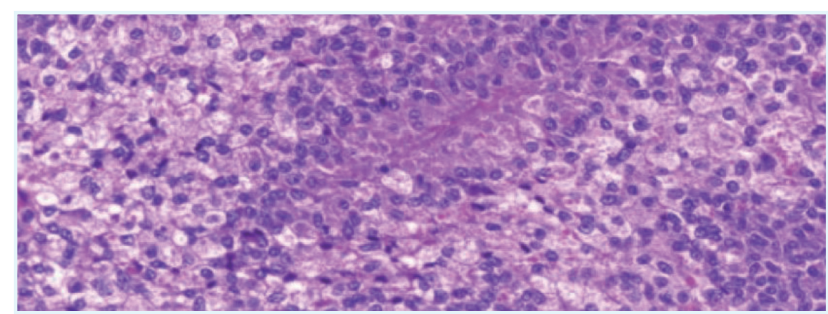

FIGURA 3. Histologia da peça cirúrgica compatível com neoplasia sólida pseudopapilar do pâncreas.

\section{DISCUSSÃO/CONCLUSÃO}

A neoplasia sólida pseudopapilar do pâncreas é rara, habitualmente de crescimento indolente, e afeta predominantemente mulheres jovens, entre os 20 e 40 anos (média de 28 anos). Nos homens tende a ser mais agressiva e a ocorrer em idades mais avançadas. ${ }^{3}$ Não parece existir predileção étnica ou associação a síndromes clínicas ou genéticas. ${ }^{1}$

A origem não é clara, contudo a maior incidência em muIheres jovens levanta a hipótese de eventual influência hormonal no seu desenvolvimento. ${ }^{3}$ Pode distribuir-se em todos os segmentos do pâncreas, embora seja reportado um ligeiro aumento nas porções distais $2,{ }^{1}$ como no presente caso localizado à cauda.

Macroscopicamente, são massas solitárias, de grande tamanho e bem delimitadas, com diâmetro médio de 6 $\mathrm{cm}$, separadas do restante tecido pancreático adjacente por uma cápsula fibrosa ${ }^{3}$ e podem ser confundidas com pseudoquistos. ${ }^{1}$ Histologicamente, com aparência microscópica distinta e padrão de crescimento heterogéneo, com estruturas pseudoquísticas, sólidas, pseudopapilares e necro-hemorrágicas em proporções variadas. ${ }^{1}$ O diagnóstico diferencial inclui neoplasias pancreáticas neuroendócrinas e tumores de células acinares. ${ }^{1}$

A nível molecular/citogenético, estão descritas mutações pontuais no exon 3 do gene da $\beta$-catenina (CTNNB1) presentes em mais de $90 \%$ casos. ${ }^{4}$ A mutação resulta na acumulação de $\beta$-catenina no citoplasma e formação de complexos $\beta$-catenin-Tcf/Lef, que por sua vez ativam genes oncogénicos como MYC e Ciclina D1.5 Apresentam um padrão imunohistoquímico característico, em quase todos com expressão nuclear de beta-catenina, vimentina, CD56, CD10, RP, alfa-1 antitripsina, alfa-1 antiquimiotripsina, enolase neurónio-específica, galactina-3, claudina 5 e 7 , ciclina D1 e recetores progesterona. ${ }^{1} \mathrm{~A}$ expressão imunohistoquímica de CD10 e vimentina, bem como a expressão anormal nuclear com anticorpos de B-catenina, e negatividade para cromogranina A e enzimas exócrinas (tripsina e quimiotripsina), auxiliam no diagnóstico diferencial entre neoplasias pancreáticas neuroendócrinas e tumores de células acinares. ${ }^{1}$
O diagnóstico é na maioria das vezes incidental, em TC ou RM solicitados por rotina ou sintomas inespecíficos. ${ }^{6}$ Habitualmente são assintomáticos a não ser que atinjam grandes dimensões. ${ }^{1}$ Quando sintomáticos, podem causar dor ou distensão abdominal, saciedade precoce, perda ponderal ou pancreatite. A icterícia obstrutiva é rara (1\%), habitualmente por lesões localizadas na cabeça do pâncreas. ${ }^{1}$

Fatores de mau prognóstico incluem: tamanho superior $5 \mathrm{~cm}$, género masculino, necrose, atipia celular, invasão vascular, perineural ou de estruturas adjacentes. ${ }^{5}$

Recomenda-se a ressecção cirúrgica em todos os pacientes, com bordos cirúrgicos livres, sendo que estes apresentam bom prognóstico a longo prazo.? Apesar de raras, as ressecções massivas em bloco, podem ocorrer na presença de invasão de órgãos vizinhos ou estruturas vasculares, ${ }^{5}$ neste caso realizada por compressão e invasão da veia esplénica, bem como contacto com vísceras ocas do hipocôndrio e flanco esquerdos. Para lesões irressecáveis, alguns esquemas de quimioterapia e o uso da radioterapia tem sido indicado, apesar de não existirem conclusões definitivas. ${ }^{8} \bigcirc$ uso de quimioterapia ou radioterapia adjuvante mantém-se questionável. ${ }^{9}$

Os tumores sólidos pseudopapilares têm curso indolente e crescimento lento, com taxa de mortalidade inferior a 2\%. ${ }^{1}$ Cerca de $85 \%$ dos doentes apresentam doença localizada ao diagnóstico, sendo que 10\%-15\% têm doença disseminada, sobretudo nos gânglios linfáticos, fígado, baço, cólon, e mesocólon. ${ }^{9}$ Quando a ressecção é completa, o prognóstico a longo prazo é excelente, com taxa de sobrevida aos 5 anos de 95\%.7 Recomenda-se follow-up, para monitorizar possível recidiva local ou metástases a distância. ${ }^{1}$

Ainda que a histologia do gânglio e do tumor não pareçam estar relacionadas, sabe-se que em até 15\% dos casos, possa existir doença disseminada, nomeadamente com envolvimento linfático. Após remoção cirúrgica do tumor verificou-se o desaparecimento das adenopatias cervicais presentes ao diagnóstico. $\bigcirc$ doente mantém-se em follow-up em consulta de Medicina, sem recidiva de adenopatias até ao momento, o que poderá inferir o envolvimento linfático secundário pela neoplasia.

\section{RESPONSABILIDADES ÉTICAS}

CONFLITOS DE INTERESSE: Os autores declaram a inexistência de conflitos de interesse na realização do presente trabalho.

FONTES DE FINANCIAMENTO: Não existiram fontes externas de financiamento para a realização deste artigo. 
CONFIDENCIALIDADE DOS DADOS: Os autores declaram ter seguido os protocolos da sua instituição acerca da publicação dos dados de doentes.

CONSENTIMENTO: Consentimento do doente para publicação obtido.

PROVENIÊNCIA E REVISÃO POR PARES: Não comissionado; revisão externa por pares.

\section{ETHICAL DISCLOSURES}

CONFLICTS OF INTEREST: The authors have no conflicts of interest to declare.

FINANCING SUPPORT: This work has not received any contribution, grant or scholarship.

CONFIDENTIALITY OF DATA: The authors declare that they have followed the protocols of their work center on the publication of data from patients.

PATIENT CONSENT: Consent for publication was obtained.

PROVENANCE AND PEER REVIEW: Not commissioned; externally peer reviewed.

\section{REFERÊNCIAS}

1. Nagtegaal ID, Odze RD, Klimstra D, Paradis $\bigvee$, Rugge M, Schirmacher P, et al: WHO Classification of Tumours Editorial Board. The 2019 WHO classification of tumours of the digestive system. Histopathology. 2020;76:182-8. doi: 10.1111/ his.13975.

2. Guimarães LS, de Melo AM, Ruiz MR, Viana JS, da Silva Junior RA. Solid pseudopapillary tumor of the pancreatic: evaluation of clinical, radiological and surgical profiles. Rev Col Bras Cir. 2013;40:398-403.

3. Vassos N, Agaimy A, Klein P, Hohenberger W, Croner RS. Solid-pseudopapillary neoplasm (SPN) of the pancreas: case series and literature review on an enigmatic entity. Int J Clin Exp Patho. 2013;6:1051-9.

4. Erráez-Jaramillo PJ, Ortiz-Hidalgo C. El diagnóstico histológico e inmunohistoquímico de la neoplasia sólida pseudopapilar de páncreas y su diagnóstico diferencial. Rev Esp Patol. 2019;52:178-89. doi: 10.1016/j.patol.2019.03.001.

5. Boyle JJ. Surgical Pathology of the GI Tract, Liver, Biliary Tract and Pancreas. Gut. 2005;54:1350. doi: 10.1136/ gut.2005.068221.

6. Yin Q, Wang M, Wang C, Wu Z, Yuan F, Chen K, et al. Differentiation between benign and malignant solid pseudopapillary tumor of the pancreas by MDCT. Eur J Radiol. 2012;81:30108. doi: 10.1016/j.ejrad.2012.03.013.

7. Antoniou EA, Damaskos C, Garmpis N, Salakos C, Margonis GA, Kontzoglou K, et al. Solid Pseudopapillary Tumor of the Pancreas: A Single-center Experience and Review of the Literature. In Vivo. 2017;31:501-10. doi: 10.21873/invivo.11089.

8. Torres OJ, Rezende MB, Waechter FL, Neiva RF, Moraes-Junior JM, Torres CS, et al. Pancreatoduodenectomy for solid pseudopapillary tumor of the pancreas: A multi-institution study Arq Bras Cir Dig. 2019;32:e1442. doi: 10.1590/0102$672020190001 \mathrm{e} 1442$.
9. Jakhlal N, Njoumi N, Hachi H, Bougtab A. Tumeur pseudopapillaire et solide du pancréas: à propos d'un cas et revue de la literature. Pan Afr Med J. 2016;24:104. doi: 10.11604/ pamj.2016.24.104.8301. 